\title{
Arctic tropospheric warming amplification?
}

\author{
Arising from: R. G. Graversen, T. Mauritsen, M. Tjernström, E. Källén \& G. Svensson Nature 451, 53-56 (2008)
}

Relative rates of temperature change between the troposphere and surface, and the mechanisms that produce these changes, have long been a contentious issue. Graversen et al. ${ }^{1}$, predicated upon the ERA-40 reanalysis ${ }^{2}$, report polar tropospheric amplification of surface warming and attempt to explain this finding dynamically. Here we show (1) that data from satellites ${ }^{3,4}$ and weather balloons ${ }^{5}$ indicate that the ERA-40 trends are increasingly unrealistic polewards of $62^{\circ} \mathrm{N}$; (2) that the two other reanalyses considered ${ }^{1}$ exhibit very different polar trends; and (3) that the vertical profile of polar trends in ERA-40 is unrealistic, particularly above the troposphere. These quasi-independent strands of evidence imply that the pattern of warming in the Arctic troposphere is highly unlikely to be as given in ERA-40 and as reported by Graversen et al. ${ }^{1}$.
Reanalyses are numerical weather-prediction systems run in hindcast mode considering all globally available observations ${ }^{2}$. Strenuous efforts are made to take account of both time-varying biases in the data and the impacts of the very substantially changing mix and coverage of observations. However, many aspects of the long-term behaviour of reanalyses remain unreliable ${ }^{6,7}$ and their suitability for use in monitoring atmospheric temperature trends has been questioned by a recent expert panel ${ }^{8}$.

Comparing ERA-40 with several observational" ${ }^{3-5}$ 'lower tropospheric' retrievals (corresponding most closely with the original analysis, peaking at about $725 \mathrm{hPa}$ ) over the $62.5^{\circ} \mathrm{N}$ to $82.5^{\circ} \mathrm{N}$ latitude range (Fig. 1, left-hand panels) yields good month-to-month
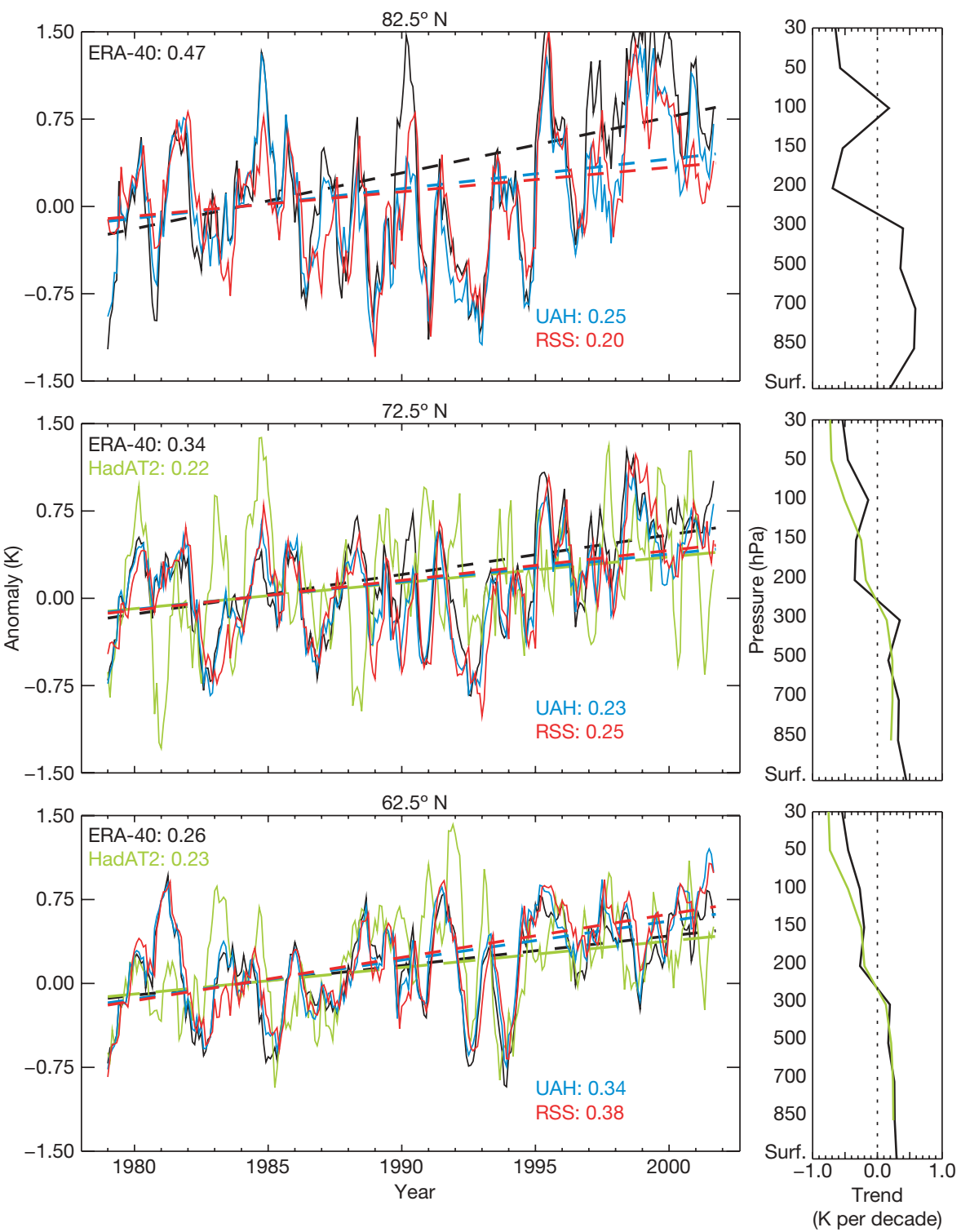

Figure 1 | Lower tropospheric retrieval data. Left-hand panels show temperature anomaly (relative to 1979-1988) monthly time series (smoothed with a simple seven-point moving filter) and trends (given as values in-line, for example ERA-40: 0.47) for three zonal bands for the broad T2LT lower tropospheric retrieval of the MSU record from UAH (ref. 3), RSS (ref. 4) and weighted equivalents from ERA-40 (ref. 2) and HadAT2 (ref. 5).
Trends, calculated using a median-of-pairwise-slopes method ${ }^{14}$, are quoted in kelvin per decade within each panel for the common period of record. Right-hand panels show vertically resolved trends on the nine HadAT2 levels for ERA-40 and HadAT2 (ref. 5). There are insufficient long-term radiosonde records at $82.5^{\circ} \mathrm{N}$ to assess climate trends, so there are no data here in HadAT2. 
agreement, particularly with the globally complete satellite records, in accord with Graversen et al. ${ }^{1}$. Crucially, however, trends increasingly diverge as the pole is approached. High-frequency agreement is insufficient to ensure that the trend will be well characterized ${ }^{9}$. At $82.5^{\circ} \mathrm{N}$, ERA-40 is overestimating the warming vis-à-vis available direct observational estimates by around $100 \%$. It is north of about $80^{\circ} \mathrm{N}$ that ERA-40 shows the substantial warming reported by Graversen et al. ${ }^{1}$. At these latitudes, however, there are very few either conventional or space-based observations available to constrain the reanalyses. Therefore, the reality of these trends, given the lack of support from the available observational estimates ${ }^{3,4}$ at $82.5^{\circ} \mathrm{N}$, must be questioned.

Indeed, a comparison of Fig. 1 of Graversen et al. ${ }^{1}$ with their Supplementary Figs 2 and 3 shows that the trend is not robust across different reanalyses systems. Although NCEP (ref. 10) can be considered a first-generation reanalysis, both ERA-40 (ref. 2) and the even newer JRA-25 (ref. 11) are second-generation reanalyses. The degree of pattern correspondence between these is visually poor, and the trend magnitudes differ substantially. This lack of robustness of the reported Arctic amplification signal implies that it is not necessarily a real-world feature.

Finally, a consideration of the full atmospheric profile rather than just that below $250 \mathrm{hPa}$ shows that the ERA-40 trends become increasingly unrealistic with latitude (Fig. 1, right-hand panels). At $62.5^{\circ} \mathrm{N}$, where radiosondes reporting temperatures, humidity and winds on distinct levels are plentiful, the ERA-40 trend looks realistic. Farther north, however, the availability of in situ radiosondes declines and the reanalysis is effectively unconstrained by in situ observations. Beyond $82.5^{\circ} \mathrm{N}$, the reanalysis is constrained only by off-nadir views from infrared satellite observations. These are unlikely to be homogeneous. Furthermore, because they represent deep layers they cannot necessarily fully anchor the reanalysis temperatures, which may therefore have been affected by vertically differentiated model biases.

Taken together, the evidence implies that the reported Arctic tropospheric amplification is a non-climatic artefact in ERA-40. This reinforces the importance of treating any single data set, be it observational or derived, with extreme caution ${ }^{12}$. It does not imply that current reanalyses are unfit for the majority of purposes to which they are put. It does, however, reaffirm the importance of a properly resourced and scientifically robust attempt to create a truly climate-quality reanalysis product: a product that adequately retains long-term trend fidelity in all meteorological parameters ${ }^{13}$.

\section{Peter W. Thorne}

${ }^{1}$ Met Office Hadley Centre, FitzRoy Road, Exeter EX1 3PB, UK. e-mail: peter.thorne@metoffice.gov.uk

\section{Received 16 January; accepted 9 May 2008.}

1. Graversen, R. G., Mauritsen, T., Tjernström, M., Källén, E. \& Svensson, G. Vertical structure of recent Arctic warming. Nature 451, 53-56 (2008).

2. Uppala, S. M. et al. The ERA-40 re-analysis. Q. J. R. Meteorol. Soc. 131, 2961-3012 (2005).

3. Christy, J. R., Spencer, R. W., Norris, W. B., Braswell, W. D. \& Parker, D. E. Error estimates of version 5.0 of MSU-AMSU bulk atmospheric temperatures. J. Atmos. Ocean. Technol. 20, 613-629 (2003).

4. Mears, C. A. \& Wentz, F. J. The effect of diurnal correction on satellite-derived lower tropospheric temperature. Science 309, 1548-1551 (2005).

5. Thorne, P. W. et al. Revisiting radiosonde upper air temperatures from 1958 to 2002. J. Geophys. Res. 110, D18105 (2005).

6. Mears, C. A., Santer, B. D., Wentz, F. J., Taylor, K. E. \& Wehner, M. F. Relationship between temperature and precipitable water changes over tropical oceans. Geophys. Res. Lett. 34, doi:10.1029/2007GL031936 (2007).

7. Bengtsson, L., Hodges, K. I. \& Hagemann, S. Sensitivity of the ERA40 reanalysis to the observing system: determination of the global atmospheric circulation from reduced observations. Tellus A 56, 456-471 (2004).

8. Karl, T. R., Hassol, S. J., Miller, C. D. \& Murray, W. L. (eds) Temperature Trends in the Lower Atmosphere: Steps for Understanding and Reconciling Differences (Synthesis and Assessment Product 1.1, US Climate Change Science Program, 2006).

9. Sherwood, S. C., Titchner, H. A., Thorne, P. W. \& McCarthy, M. C. How do we tell which estimates of past climate change are correct? Int. J. Climatol. (submitted).

10. Kalnay, E. et al. The NCEP/NCAR 40-year reanalysis project. Bull. Am. Meteorol. Soc 77, 437-470 (1996)

11. Onogi, K. et al. The JRA-25 reanalysis. J. Meteorol. Soc. Jpn 85, 369-432 (2007).

12. Thorne, P. W., Parker, D. E., Christy, J. R. \& Mears, C. A. Uncertainties in climate trends - Lessons from upper-air temperature records. Bull. Am. Meteorol. Soc. 86, 1437-1442 (2005).

13. Bengtsson, L. et al. The need for a dynamical climate reanalysis. Bull. Am. Meteorol. Soc. 88, 495-501 (2007).

14. Lanzante, J. R. Resistant, robust and non-parametric techniques for the analysis of climate data: Theory and examples, including applications to historical radiosonde station data. Int. J. Climatol. 16, 1197-1226 (1996).

doi:10.1038/nature07256

\title{
Recent Arctic warming vertical structure contested
}

\author{
Arising from: R. G. Graversen, T. Mauritsen, M. Tjernström, E. Källén \& G. Svensson Nature 451, 53-56 (2008)
}

The vertical structure of the recent Arctic warming contains information about the processes governing Arctic climate trends. Graversen et al. argue $^{1}$, on the basis of ERA-40 reanalysis ${ }^{2}$ data, that a distinct maximum in 1979-2001 warm-season (April-October) Arctic temperature trends appears around $3 \mathrm{~km}$ above ground. Here we show that this is due to the heterogeneous nature of the data source, which incorporates information from satellites and radiosondes. Radiosonde data alone suggest the warming was strongest near ground.

Graversen et al. ${ }^{1}$ claim that the warm-season temperature trend has a maximum at around $700 \mathrm{hPa}$, polewards of $75^{\circ} \mathrm{N}$, and argue that anomalous heat advection from more southerly latitudes is important. However, the ERA-40 reanalysis may not be suitable for trend analysis as it incorporates information from different observing systems such as satellite and radiosonde, which might be inconsistent, in particular with respect to trends ${ }^{3,4}$. Radiosonde measurements provide vertically resolved temperature profiles in the troposphere, whereas satellites provide information on a weighted average over a thick layer. Furthermore, the ERA-40 assimilation system extrapolates information from data-rich to data-sparse areas, which is less reliable than observations. The ERA-40 reanalysis in the polar region has not been sufficiently validated by in situ observations and documented $^{2,5}$ problems with satellite radiance assimilations over the Arctic Ocean could lead to spurious trends.

A map of warm-season trends at $700 \mathrm{hPa}$ (the peak level of the polar warming trend in ref. 1) from ERA-40 and radiosonde observations $s^{6,7}$ confirms that the enhanced warming signal lies mostly in areas with no radiosonde data coverage (Fig. 1a). This is particularly so polewards of $75^{\circ} \mathrm{N}$, where the trend appears strongest in ref. 1 . Moreover, the few radiosonde data available near or polewards of $75^{\circ} \mathrm{N}$ show modest trends. To illustrate the effects on the vertical structure of the trend, we calculated zonally averaged vertical temperature trends from (1) ERA-40 reanalysis data, (2) such data subsampled to locations where radiosonde information is available (that is, where ERA-40 is best constrained) and (3) from only radiosonde data. The trend in the reanalysis (Fig. 1b) is a reproduction of Fig. $4 \mathrm{a}$ in ref. 1 and exhibits a maximum at $700 \mathrm{hPa}$, polewards of $75^{\circ} \mathrm{N}$. Subsampling the ERA-40 reanalysis (Fig. 1c) reveals clearly different trends, and calculating trends directly from radiosondes alters matters even further (Fig. 1d). The result is independent of the methods used to homogenize the radiosonde data (unadjusted, RAOBCORE v1.4 (ref. 7) and RICH (ref. 8); not shown). The radiosonde data (note that some regions are not well covered and some levels are 

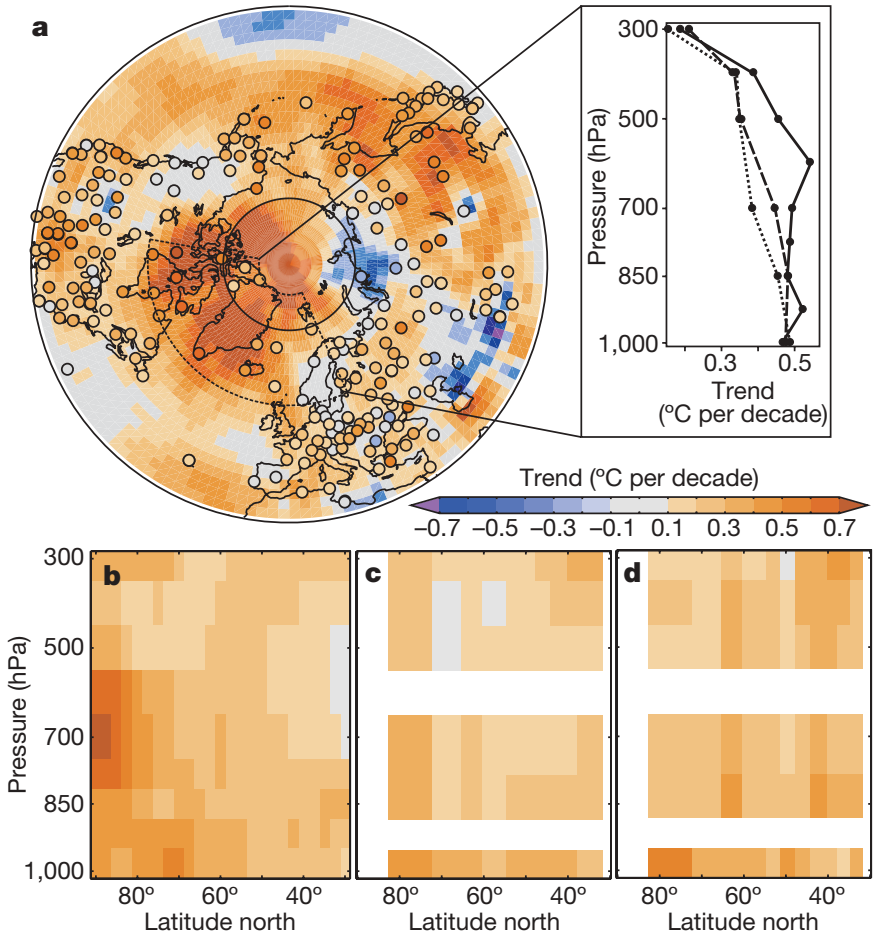

Figure 1 | Vertical structure of Arctic temperature trends for April to October, 1979-2001. Trends were calculated from seasonally averaged monthly anomalies using least-squares regression (not more than one missing month per season allowed, not more than five missing seasons in 1979-2001, neither first nor last two years can be missing). a, Trend field at $700 \mathrm{hPa}$ from ERA-40 (ref. 2) and from radiosonde data ${ }^{6,7}$ (circles) with $75^{\circ} \mathrm{N}$ latitude circle indicated by the thin solid line. $\mathbf{b}$, Trends of zonal-mean temperature as a function of latitude and altitude from ERA-40. c, Same as b, but from ERA-40 subsampled to the locations and times where radiosonde data are available (anomalies zonally averaged in equal-area latitude bands). d, Same as c, but for radiosonde data. Inset in a, average trend profiles of the region $58^{\circ} \mathrm{N}-82^{\circ} \mathrm{N}, 100^{\circ} \mathrm{W}-25^{\circ} \mathrm{E}$ for full ERA-40 (solid line), subsampled ERA-40 (dashed) and radiosonde data (dotted).

missing because of inconsistent reporting) have their strongest trend near the ground, not above the boundary layer as in the full reanalysis. This is important because boundary layer processes are much more locally driven and simultaneously not well represented in a reanalysis. The same result is found when analysing a subregion with relatively even radiosonde coverage (inset, Fig. 1a), and during the remainder of the year (not shown).

Arctic climate is controlled by processes operating on scales from local to global, including transport effects; forcings such as greenhouse gases, aerosols and clouds; and feedbacks such as the well-known seaice-albedo feedback. The temperature profile can be a clue to the underlying processes, but to disentangle the contributions to Arctic temperature trends fully, vertical temperature structures should be addressed in a regionally and seasonally resolved manner. Furthermore, the large interannual variability in the Arctic, coupled with the sensitivity of trends to both end points and season definitions, suggests care should be taken in interpreting trends over short periods.

In conclusion, some features of the temperature trends calculated in ref. 1 reflect possible inhomogeneities or artefacts in the ERA-40 reanalysis rather than true climate signals, as they appear not to be supported by observations. ERA-40 reanalysis is a valuable tool in calculating circulation effects, especially on a subdecadal basis, but inhomogeneities and gaps in the global observing system tend to make trends from reanalyses unreliable, particularly in data-sparse regions.

\section{A. N. Grant ${ }^{1}$, S. Brönnimann ${ }^{1}$ \& L. Haimberger ${ }^{2}$}

${ }^{1}$ Institute for Atmospheric and Climate Science, ETH Zurich, Universitätstrasse 16, CH-8092 Zurich, Switzerland.

e-mail: andrea.grant@env.ethz.ch

${ }^{2}$ Department of Meteorology and Geophysics, University of Vienna, Althanstrasse 14, A-1090 Vienna, Austria.

Received 23 January; accepted 12 May 2008.

1. Graversen, R. G., Mauritsen, T., Tjernström, M., Källén, E. \& Svensson, G. Vertical structure of recent Arctic warming. Nature 451, 53-56 (2008).

2. Uppala, S. M. et al. The ERA-40 re-analysis. Q. J. R. Meteorol. Soc. 131, 2961-3012 (2005).

3. Fu, Q., Johanson, C. M., Warren, S. G. \& Seidel, D. J. Contribution of stratospheric cooling to satellite-inferred tropospheric temperature trends. Nature 429, 55-58 (2004).

4. Mears, C. A. \& Wentz, F. J. The effect of diurnal correction on satellite-derived lower tropospheric temperature. Science 309, 1548-1551 (2005).

5. Bromwich, D. \& Wang, S.-H. Evaluation of the NCEP-NCAR and ECMWF 15- and 40yr reanalyses using rawindsonde data from two independent Arctic field experiments. Mon. Weath. Rev. 133, 3562-3578 (2005).

6. Durre, I., Vose, R. \& Wuertz, D. Overview of the integrated global radiosonde archive. J. Clim. 19, 53-68 (2006)

7. Haimberger, L. Homogenization of radiosonde temperature time series using innovation statistics. J. Clim. 20, 1377-1403 (2007).

8. Haimberger, L. et al. Towards elimination of the warm bias in historic radiosonde temperature records - some new results from a comprehensive intercomparison of upper air data. J. Clim. (in the press).

doi:10.1038/nature07257

\title{
Arctic warming aloft is data set dependent
}

\author{
Arising from: R. G. Graversen, T. Mauritsen, M. Tjernström, E. Källén \& G. Svensson Nature 451, 53-56 (2008)
}

Arctic sea ice and snow on land have retreated polewards at an alarming pace in the past few decades ${ }^{1}$. Such retreat locally amplifies surface warming through a positive feedback, which causes the Arctic surface to warm faster than the rest of the globe. In contrast, ice and snow retreat causes little warming in the atmosphere above when the stable winter atmosphere inhibits vertical heat exchange. We therefore find surprising the recent report by Graversen et al. ${ }^{2}$ in which they claim that recent Arctic atmospheric warming extends far deeper into the atmosphere than expected, and can even exceed the surface warming during the polar night. Using a different data set, we show that there is much less warming aloft in winter, consistent with the recent retreat of ice and snow, as well as recent changes in atmospheric heat transport.
Graversen et al. ${ }^{2}$ compute trends for 1979-2001 from ERA-40 reanalysis, which is a hybrid product using many types of raw observational data assimilated with a consistent global analysis system. The assimilation compensates for some but not all of the variations in the observing system over time that may compromise the veracity of the temperature trend analyses ${ }^{3}$. Figure 1 compares temperature trends in winter from the ERA-40 reanalysis with climate-quality records from satellite observations ${ }^{4}$. Trends in the Arctic winter aloft are strongly data set dependent: the observed trend is $75 \%$ less than reanalysis in the middle troposphere and $40 \%$ less than in the lower-middle troposphere. In comparison with the observations, the reanalysis exaggerates polar amplification aloft by overestimating the Arctic atmospheric warming and underestimating the Northern 


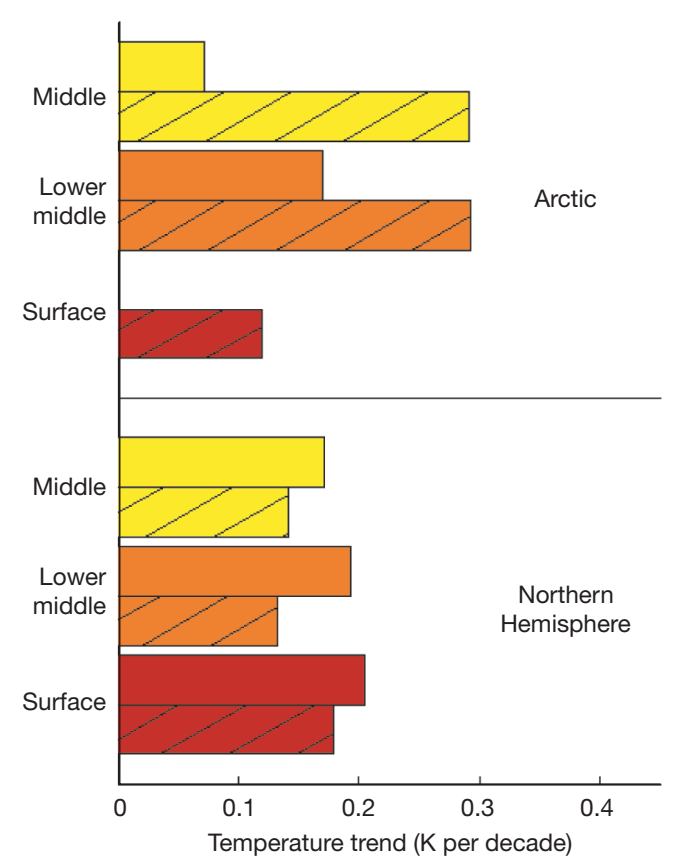

Figure 1 | Temperature trends over the Northern Hemisphere $\left(0^{\circ}-82.5^{\circ} \mathrm{N}\right)$ and the Arctic $\left(65^{\circ} \mathrm{N}-82.5^{\circ} \mathrm{N}\right)$ for 1979-2001. Trends are for temperatures at the surface and in the lower-middle and middle troposphere from the ERA-40 reanalysis (hatched) and observations (solid) in the winter (December-February) season. The observed trends are derived from the HadCrut3v (ref. 8) data set for the surface temperature and from a satellite microwave sounding unit $^{9}$ (MSU; RSS version 3) for the temperatures in the lower-middle ${ }^{10}$ and middle ${ }^{11,12}$ troposphere. Observed surface temperatures in the Arctic are not shown, because they are spatially incomplete. For a direct comparison with the MSU observations, synthetic temperatures in the lower-middle and middle troposphere are computed from the ERA-40 reanalysis by applying the MSU weighting functions ${ }^{3}$.

Hemisphere atmospheric warming in every season. Specifically, for trends in annual means in the reanalysis for 1979-2001, the Arctic warms 2.7 times more than the Northern Hemisphere in the lowermiddle troposphere, in comparison with just 1.5 times more in the observations.

During the polar night, solar absorption at the surface is absent or weak. At the same time, the atmosphere transports a substantial amount of heat northwards from lower latitudes, with heating rates in the Arctic that maximize at about $1,500 \mathrm{~m}$ in winter ${ }^{5}$. For these reasons and others, strong radiative cooling at the surface causes frequent lower-tropospheric temperature inversions, which are very stable and damp vertical heat transfer during the polar night. When ice and snow retreat, some of the heat from increased solar absorption is stored at the ocean surface and is released during the cold seasons without warming the atmosphere aloft very much.

It has been concluded that northwards atmospheric heat transport into the Arctic should increase in a warming world ${ }^{6,7}$ owing to increased evaporation in the tropics and subsequent condensation in the high latitudes. This increase in latent heat transport is somewhat counterbalanced by a decrease in sensible heat transport, as Arctic amplification decreases the pole-to-equator temperature gradient. Models indicate that warming aloft would not outpace the surface warming after considering increased northwards atmospheric heat transport along with the retreat of ice and snow ${ }^{7}$. Graversen et al. ${ }^{2}$ find that the change in northwards atmospheric heat transport is not a substantial source of heating aloft in midwinter (January-February) in the Arctic.

The smaller warming trends aloft in the observations in winter are more consistent with the amplification of surface warming from ice and snow retreat and the lack of change in the northwards atmospheric heat transport for 1979-2001. This consistent set of observations calls into question the results of Graversen et al. ${ }^{2}$ obtained for the polar night.

\section{Cecilia M. Bitz \& Qiang Fu ${ }^{1}$}

${ }^{1}$ Atmospheric Science Department, 408 Atmospheric Sciences and Geophysics Hall, University of Washington, Seattle, Washington 98195, USA. e-mail: bitz@atmos.washington.edu

\section{Received 5 February; accepted 9 May 2008.}

1. Lemke, P. et al. in Climate Change 2007: The Physical Science Basis (eds Solomon, S. et al.) 337-383 (Contribution of Working Group I to the Fourth Assessment Report of the IPCC, Cambridge Univ. Press, 2007).

2. Graversen, R. G., Mauritsen, T., Tjernström, M., Källén, E. \& Svensson, G. Vertical structure of recent Arctic warming. Nature 451, 53-56 (2008).

3. Johanson, C. M. \& Fu, Q. Antarctic atmospheric temperature trend patterns from satellite observations. Geophys. Res. Lett. 34, doi:10.1029/2006GL029108 (2007).

4. Karl, T. R., Hassol, S. J., Miller, C. D. \& Murray, W. L. (eds) Temperature Trends in the Lower Atmosphere: Steps for Understanding and Reconciling Differences (Synthesis and Assessment Product 1.1, US Climate Change Science Program, 2006).

5. Overland, J. E. \& Turret, P. in The Polar Oceans and Their Role in Shaping the Global Environment (eds Johannessen, O. M., Muench, R. \& Overland, J. E.) 313-325 (American Geophysical Union, 1994).

6. Alexseev, V. A., Langen, P. L. \& Bates, J. R. Polar amplification of surface warming on an aquaplanet in "ghost forcing" experiments without sea ice feedbacks. Clim. Dyn. 24, 655-666 (2005).

7. Cai, M. \& Lu, J. Dynamical greenhouse-plus feedback and polar warming amplification. Part II: meridional and vertical asymmetries of the global warming. Clim. Dyn. 29, 375-391 (2007).

8. Brohan, P., Kennedy, J. J., Haris, I., Tett, S. F. B. \& Jones, P. D. Uncertainty estimates in regional and global observed temperature changes: A new data set from 1850. J. Geophys. Res. 111, doi:10.1029/2005JD006548 (2006).

9. Mears, C. A., Schabel, M. C. \& Wentz, F. J. A reanalysis of the MSU channel 2 tropospheric temperature record. J. Clim. 16, 3650-3664 (2003).

10. Mears, C. A. \& Wentz, F. J. The effect of diurnal correction on satellite-derived lower tropospheric temperature. Science 309, 1548-1551 (2005).

11. Fu, Q., Johanson, C. M., Warren, S. G. \& Seidel, D. J. Contribution of stratospheric cooling to satellite-inferred tropospheric temperature trends. Nature 429, 55-58 (2004).

12. Johanson, C. M. \& Fu, Q. Robustness of tropospheric temperature trends from MSU channels 2 and 4. J. Clim. 19, 4234-4242 (2006).

doi: $10.1038 /$ nature 07258

\section{Graversen et al. reply}

Replying to: P. W. Thorne Nature 455, doi:10.1038/nature07256; A. N. Grant, S. Brönnimann \& L. Haimberger Nature 455, doi:10.1038/ nature07257; C. M. Bitz \& Q. Fu Nature 455, doi:10.1038/nature07258 (2008)

These three communications ${ }^{1-3}$ question the validity of some of our conclusions ${ }^{4}$. We found Arctic temperature trend amplification well above the boundary layer. In summer, the maximum amplification is found at a height of around $2 \mathrm{~km}$, and no amplification is encountered near the surface. These findings appear in two state-of-the-art reanalyses, ERA-40 (ref. 5) and JRA-25 (ref. 6). Both these data sets show roughly the same overall vertical structure, and we believe our conclusions can be based on either of them. However, they show 
considerable differences regarding the magnitudes of the Arctic trends (see our Supplementary Information ${ }^{4}$ ), but our conclusions are not based on the absolute magnitudes.

A reanalysis synthesizes all available observations and uses a physically based model of the atmosphere to weigh the observations against each other and to extrapolate the observed information in space and time to unobserved parts of the atmosphere. The assimilation procedure takes observational as well as model uncertainties into account. In ERA-40 and JRA-25, the strongest observational constraint on the Arctic temperatures aloft is provided by assimilation of satellite observations, such as microwave sounding unit (MSU) radiances, as in situ observations are few in this region. In the assimilation process, careful bias adjustment has been applied to the satellite observations ${ }^{5}$.

We examined the agreement of the MSU satellite observations (RSS analysis ${ }^{7}$ TLT v3.1 and TMT v3.2) with the vertical structure of ERA-40 and JRA-25. Arctic amplification is encountered in the channel representing the lower troposphere. In summer, both the lower-troposphere and the middle-troposphere channels indicate considerable warming over the Arctic. Because the Arctic surface temperature is constrained to be close to the melting point during this season, this warming must occur aloft, in accordance with the two reanalyses.

The annual lower-troposphere MSU trend reaches $0.46 \mathrm{~K}$ per decade at $81.25^{\circ} \mathrm{N}$, calculated on the basis of a least-squares fit. We therefore find it surprising that Thorne ${ }^{1}$ estimates a high-latitude trend of only $0.2 \mathrm{~K}$ per decade. Bitz and $\mathrm{Fu}^{3}$ report winter trends in the lower troposphere of around $0.2 \mathrm{~K}$ per decade both for the Arctic and the Northern Hemisphere, which we also find. However, they report middle-troposphere trends of around 0.09 and $0.18 \mathrm{~K}$ per decade for the Arctic and the Northern Hemisphere, respectively. We find, on the other hand, 0.14 and $0.09 \mathrm{~K}$ per decade for the Arctic and the Northern Hemisphere, respectively. Hence, the MSU data show winter Arctic amplification in agreement with ERA-40 and JRA-25.

In their last paragraph, Bitz and $\mathrm{Fu}^{3}$ indicate that ERA-40 exaggerates winter trends aloft. This might be the case; JRA-25 shows considerably smaller trends. However, our point is that, even in JRA-25, winter trends above the boundary layer are comparable to those near the surface and can hardly be linked to surface processes alone. Grant et al. ${ }^{2}$ compare ERA-40 data with radiosonde observations, which are few in the Arctic. Although these observations cannot confirm the April-October warming aloft found in ERA-40, in general they show good agreement with the ERA-40 data at the points where radiosondes are available.

There is no doubt that more in situ observations in the Arctic are needed to enhance the quality of future reanalyses. Given the absence of such observations in historical archives, we feel that a reanalysis is likely to provide a better representation of the true state of the Arctic atmosphere than any single inhomogeneous set of a specific observation type. Satellite observations must be bias corrected and radio soundings exist almost only in the southern part of the Arctic. In a reanalysis, both of these shortcomings are consistently handled in the framework of a dynamical, global model of the atmosphere. We have given an estimate of the uncertainty associated with reanalysis data by displaying results from two different, second-generation reanalyses. Within the limits of this uncertainty we believe that our conclusions remain valid.

\section{R. G. Graversen ${ }^{1}$, T. Mauritsen ${ }^{1}$, M. Tjernström ${ }^{1}$ E. Källén ${ }^{1}$ \& \\ G. Svensson ${ }^{1}$}

${ }^{1}$ Department of Meteorology, Stockholm University, S-106 91 Stockholm, Sweden.

e-mail: rune@misu.su.se

1. Thorne, P. W. Arctic tropospheric warming amplification? Nature 455, doi:10.1038/ nature07256 (2008)

2. Grant, A. N., Brönnimann, S. \& Haimberger, L. Recent Arctic warming vertical structure contested. Nature 455, doi:10.1038/nature07257 (2008).

3. Bitz, C. M. \& Fu, Q. Arctic warming aloft is data set dependent. Nature 455 , doi:10.1038/nature07258 (2008).

4. Graversen, R. G., Mauritsen, T., Tjernström, M., Källén, E. \& Svensson, G. Vertical structure of recent Arctic warming. Nature 451, 53-56 (2008).

5. Uppala, S. M. et al. The ERA-40 re-analysis. Q. J. R. Meteorol. Soc. 131, 2961-3012 (2005).

6. Onogi, K. et al. The JRA-25 reanalysis. J. Meteorol. Soc. Jpn 85, 369-432 (2007)

7. Mears, C. A. \& Wentz, F. J. The effect of diurnal correction on satellite-derived lower tropospheric temperature. Science 309, 1548-1551 (2005).

doi:10.1038/nature07259 